\title{
Da Integração Energética À Integração Política: a Adoção de uma Política Energética Comum como Eixo da InTegração Sul-Americana
}

\author{
Ricardo Barretto de Andrade (*)
}

\begin{abstract}
Resumo: Este trabalho tem por objetivo analisar a viabilidade da adoção, pelos países sul-americanos, de uma Política Energética Comum — PEC, voltada ao planejamento e à gestão do setor, visando à integração energética e, a partir dessa, o fortalecimento da integração política regional. Para tanto, inicialmente é realizada uma abordagem teórica que expõe dois importantes paradigmas de integração regional: o paradigma liberal e o paradigma "regional-desenvolvimentista". Depois, a par tir da exposição de um breve histórico da integração latino-americana, são enumeradas algumas das causas responsáveis pelo declínio das principais experiências da região nessa área em passado recente. Como alternativa ao modelo comercialista tradicionalmente adotado nos esquemas de integração latino-americanos, o trabalho busca na experiência da integração europeia o conceito de política comunitária setorial. A partir disso, envereda-se pela questão energética, expondo o potencial desses países nesse tema, do que decorre a possibilidade de êxito de uma PEC na região, com objetivos setoriais, estratégicos e políticos. Por fim, formulam-se algumas sugestões para a atuação conjunta dos países sul-americanos no setor energético bem como são mencionados os resultados que podem ser esperados de uma política regional comum nesse sentido.
\end{abstract}

Palavras-chave: Integração Regional, Energia, Desenvolvimento Econômico, América do Sul.

\begin{abstract}
This study aims to examine the feasibility of implementing by South American countries a common energy policy - CEP — which will plan and manage the sector, with the objective of integrating energy, and from this, strengthening the regional political integration. Thus, it is initia-lly performed a theoretical approach that exposes two major paradigms for regional integration: the liberal paradigm and "regional-developmental" paradigm. Then, from the exposure of a brief history of Latin American integration, it is listed the most important causes for the declining of the region's main experiences in this area in the recent past. As an alternative to the commercialistic schemes traditionally used in Latin American integration, this study seeks in the experience of the European integration the concept of sectoral policy. From it, we expose the energy issue, emphasizing the potential of these countries in this field. This factor increases the likelihood of the CEP success in the region based on sectoral objectives, strategies and specific policies. Finally, we make few suggestions for joint action of the South American countries in the energy sector.
\end{abstract}

Keywords: Regional Integration, Energy, Developmental, Economic Political, South American.

\footnotetext{
(*) Advogado e Internacionalista. Graduado em Direito pela Universidade Federal da Bahia (UFBA) e em Relações Internacionais pelas Faculdades Jorge Amado (FJA).E-mail: randrade4545@bol.com.br. Recebido em 26.6.09 e aceito em 6.7.09.
} 


\section{INTRODUÇÃo}

Os países da América do Sul possuem em comum diversos fatores históricos e culturais que tornam sua integração uma realidade factível. Além disso, o aprofundamento da integração sul-americana tornou-se um imperativo diante do excludente processo de globalização em curso, que reserva aos países subdesenvolvidos, por meio de uma inserção internacional subordinada, a permanente condição de periferia no sistema internacional.

Posta a necessidade premente de um entendimento entre os Estados da América do Sul, vale discutir quais temas devem nortear sua integração. Nesse ponto, questiona-se a eficácia de longo prazo de esquemas de integração regional baseados exclusivamente no intercâmbio comercial. As experiências sul-americanas na formação de blocos econômicos confirmam que, a rigor, um processo de integração que tenha como escopo a mera questão comercial, em geral, além de apresentar mais instabilidade decorrente de disputas comerciais internas, está sujeito a sofrer profundos retrocessos ou mesmo desaparecer, caso um de seus membros eventualmente passe por uma crise econômica que reduza em grande medida suas importações.

Ora, a integração regional na América do Sul deve ter um sentido estratégico muito maior e não pode ficar restrita apenas a questões de ordem comercial, para que, assim, os países da região disponham de uma inserção internacional altiva e mais soberana. Analisaremos neste estudo a adoção, pelos países sul-americanos, de uma Política Energética Comum - PEC, como uma estratégia viável de integração e de geração de desenvolvimento para esses países.

\section{INTEGRAÇ̃̃o REGIONAL: BREVE DISCUSSÃo TEÓRICA}

\section{LibERALISMO E INTEGRAÇÃo REGIONAL}

A aplicação do paradigma liberal à integração regional apresenta alguns inconvenientes, principalmente no que se refere à percepção dos temas que devam ser objeto da integração e do papel a ser ocupado pelos estados nesse processo. No que concerne à temática do processo de integração, o paradigma liberal apenas vislumbra o aspecto comercial da integração econômica. Entende-se a integração regional como um instrumento de liberalização de mercados a ser aplicado no âmbito de um bloco composto por alguns países.

Ao tratar da ideologia dos processos de integração implementados na América Latina, Schaposnik (1997. p. 39) afirma que há um desacordo fundamental acerca do modelo, da ideologia desse modelo, dos objetivos e dos mecanismos que se devem instrumentar para cumprir os propósitos perseguidos. Mais adiante, ao se referir à constante crise histórica enfrentada pela integração latino-americana, arremata:

É fácil advertir que as teorias neoclássicas impuseram-se finalmente e os resultados da crise que hoje estamos analisando advêm da aplicação de ideias de liberalização econômica e aplicação de princípios não localistas, na economia da América Latina (SCHAPOSNIK, 1997, p. 41). 
Dessa forma, na integração latino-americana, sobretudo com a Área Latino-Americana de Livre Comércio (ALALC), na década de 1960, dimensionou-se de forma excessiva e inadequada o papel exercido pelo comércio intrarregional. Schaposnik (1997, p. 44) salienta que no trânsito de um modelo comercialista de integração para um modelo de desenvolvimento econômico e social, há uma mudança muito importante. Assim, a ausência de políticas estruturais comuns foi uma das razões da não sustentação da ALALC, assim como outros processos de integração, sequer enquanto processo de integração exclusivamente comercial.

Outro ponto fundamental à integração regional, a ser discutido no bojo do pensamento liberal, refere-se ao papel que deve ser desempenhado pelos entes estatais nesses processos de integração, se de apenas agentes em prol da liberalização do comércio regional ou de atores pró-ativos, fomentadores de uma integração lastreada não apenas em questões comerciais, mas também em estratégias econômicas, sociais, políticas e culturais. Essa controvérsia, existente no âmbito interno dos países, também deve ser suscitada no contexto da integração regional.

A lógica liberal é de que os Estados devem limitar sua atuação à garantia do livre comércio no seio da integração econômica, destacando o papel do capital privado nesse processo. No atual estágio da globalização econômica, esse posicionamento equivale à defesa de que se transfira às empresas transnacionais a responsabilidade por dirigir os rumos da integração latino-americana.

Nesses termos, é fundamental que seja discutida a configuração de um modelo político e econômico que venha a nortear a integração latino-americana. Esse modelo deverá passar necessariamente pelo protagonismo dos entes estatais e pela ampliação efetiva dos temas e dos setores a serem trabalhados nesse processo.

\section{Paradigma Regional-Desenvolvimentista}

Em contraposição ao paradigma liberal, pode-se falar num paradigma regionaldesenvolvimentista para a integração latino-americana. Para tanto, são de grande relevância: 1) a participação ativa dos Estados na integração regional, atuando como fomentadores da integração e do desenvolvimento regional; e 2) a diversificação dos temas objeto da integração e seleção de setores estratégicos que merecem especial atenção e que, por essa razão, ensejam planejamento e implementação de longo prazo, o que deve ser feito por intermédio de uma política setorial comum à agenda dos países envolvidos.

\section{O PAPEL DO ESTADO NO PARADIGMA REGIONAL-DESENVOLVIMENTISTA DE INTEGRAÇÃo}

A formulação de um paradigma de integração regional-desenvolvimentista não pode prescindir de uma exposição a respeito de que papel deve ser desempenhado pelos entes estatais num processo de integração regional e, particularmente, na integração latino-americana.

Assim, o paradigma regional-desenvolvimentista corresponde a um modelo no qual os Estados têm papel central na mobilização dos segmentos econômicos e sociais, dessa forma promovendo e dinamizando o ambiente de integração. No caso da América Latina, mais do que ocorre nos países desenvolvidos, a função indutora que têm os Estados nos 
processos de integração regional é ainda mais fundamental para viabilizar e sustentar esse tipo de iniciativa.

Isso porque os países latino-americanos ainda não possuem seus setores produtivos tão desenvolvidos e internacionalizados como, por exemplo, o empresariado europeu e norte-americano. Logo, o papel que o Estado deve desempenhar na integração da América Latina é muito superior ao que exerceu na Europa, tanto em intensidade quanto em quantidade de setores socioeconômicos.

Assim, num processo de integração regional não se pode conceber os Estados enquanto meros signatários de acordos que apenas viabilizam a redução ou eliminação de barreiras ao livre comércio, seja porque eles têm a função essencial de fomentar permanentemente a integração, ou, ainda, porque a integração regional empreendida com vistas ao desenvolvimento não pode se restringir a meras questões comerciais.

No particular, percebe-se que há uma óbvia vinculação entre a percepção liberal de que o Estado tem um papel reduzido no processo de integração regional e a restrição da temática de integração às questões comerciais, tal como ocorre na América Latina. Ora, a partir do pressuposto de que o Estado deve ter uma atuação limitada no contexto da integração regional, deixando à iniciativa privada a responsabilidade de elevar os fluxos de comércio e capitais intrabloco, duas conclusões podem ser extraídas:

1) Essa ideologia exclui a possibilidade de que a integração regional se desenvolva em setores não rentáveis ou de rentabilidade muito demorada à iniciativa privada. Via de regra, esses investimentos são estratégicos, porquanto essenciais à sustentabilidade da integração no longo prazo, bem como à geração de desenvolvimento regional. Por exemplo, os setores energético e de infraestrutura de integração física demandam elevado volume de investimentos e dilatado tempo para proporcionar retorno. Assim, os Estados nacionais devem ter um papel bastante ativo na integração regional, sobretudo quando se trata de países não desenvolvidos.

2) Essa mesma lógica, ao delegar à iniciativa privada a atividade comercial, entendida como principal eixo da integração, retira dos Estados nacionais a função de conduzir os processos de integração dos quais fazem parte.

Dessa maneira, a integração regional baseada no modelo aplicado na América Latina carece de políticas regionais setoriais realizadas em conjunto pelos Estados, razão pela qual a própria existência desse tipo de processo integracionista fica condicionada tão somente à evolução do intercâmbio comercial entre os países envolvidos.

É de se supor, desse modo, que a integração regional, caso continue baseada apenas no comércio intrarregional, poderá estar fadada ao fracasso, tal como ocorreu em diversos processos de integração regional latino-americanos.

\section{A IntegraÇão latino-Americana diante da INTEgRaÇão EUROPEIA}

\section{BREVE HISTÓRICO DA INTEGRAÇÃo LATINO-AMERICANA}

No ano de 1960, foi criada a ALALC, formada por todos os países da América do Sul mais o México, que tinha o objetivo de estabelecer uma zona de livre comércio. Nessa 
época, os países da região alimentavam, com apoio da Comissão Econômica para a América Latina e o Caribe (CEPAL), a expectativa de impulsionar o processo de industrialização.

Apesar de ter empreendido importantes iniciativas de integração numa América Latina quase completamente isolada, o grande objetivo da ALALC era a liberalização comercial entre seus países integrantes, razão pela qual o processo de negociação das listas nacionais de produtos sujeitos ao comércio preferencial teve um início auspicioso e nos primeiros anos logrou incrementar rapidamente o número de preferencias outorgadas (ROSENTHAL, 1991, p. 62).

Com o passar do tempo, todavia, o processo se tornou cada vez mais lento, até se tornar praticamente estancado a partir do fim da década de 1960 (ROSENTHAL, 1991, p. 62). Isso ocorreu justamente porque a ALALC se baseou numa perspectiva essencialmente comercialista e esse modelo não se sustentou por muito tempo, entrando em crise a partir do momento que os países se mostraram cada vez menos dispostos a negociar (ROSENTHAL, 1991, p. 62). Diante das dificuldades enfrentadas pela ALALC, foi concebido, em sua substituição, um novo modelo de integração que veio a ser denominado de Associação Latino-Americana de Integração (ALADI).

A ALADI, que nos dizeres de Menezes e Penna Filho (2006, p. 17), foi a alternativa encontrada para dizer formalmente que a tentativa de integração econômica continuava a existir. Por esse motivo, todo o processo foi flexibilizado, pelo que não mais havia prazos rígidos para a eliminação de barreiras alfandegárias como antes. Manteve-se, portanto, foco prioritariamente nas questões relativas à liberalização comercial.

Já o Mercosul é uma estrutura de integração sub-regional criada a partir da formação de uma união aduaneira entre seus membros signatários, pelo que foi instituída uma Tarifa Externa Comum. Com isso não se pretende afirmar que o Mercosul seja um esquema de integração regional estritamente direcionado ao comércio, mas não há dúvida de que os demais temas não possuem a mesma visibilidade e atenção política que as questões comerciais nas negociações do bloco.

\section{Principais causas da insustentabilidade da integração latino-americana}

A integração regional latino-americana, via de regra, pautou-se pela integração meramente comercial, o que sujeita a própria existência do processo ao volume das trocas de bens e serviços entre os países membros. Dessa forma, a integração é apenas pensada no curto prazo, em termos da liberalização comercial intrabloco, o que pressupõe uma reduzida participação do Estado nos rumos da integração, que caberia à iniciativa privada.

Com base nesse propósito de integração, aprofundado ainda mais na América Latina na década de 1980, em razão da assunção de modelos neoliberais, fica evidente que a integração latino-americana é vulnerável e frágil por estar constantemente sujeita a retrocessos oriundos de eventuais adversidades da economia mundial. Por esse motivo, para que se alcance um modelo integracionista sustentável, deve ser ampliado o espectro da integração entre os países da América Latina, viabilizando, com isso, a criação de vínculos em diversos setores econômicos, de infraestrutura, sociais, políticos e culturais que mantenha 
viva e intensa a integração regional mesmo em momentos de crise econômica e decorrente redução dos níveis de intercâmbio comercial.

Apenas dessa maneira se poderá pôr em prática a verdadeira dimensão que deve ter a integração para os países latino-americanos, originalmente pensada como instrumento de defesa coletiva contra as adversidades surgidas no setor externo, hoje tende a ser concebida como um elemento mais ofensivo, que contribua para melhorar a inserção internacional da América Latina (ROSENTHAL, 1991, p. 67). A integração, portanto, não é apenas um instrumento de relevância defensiva, mas um elemento de importância ativa para o desenvolvimento latino-americano, que passa, necessariamente, por uma inserção internacional política e economicamente soberana para a região.

Ademais, vale mencionar o fundamental papel que têm os Estados nacionais latino-americanos na condução da integração regional e no planejamento de políticas setoriais comuns que nortearão o desenvolvimento das diferentes áreas de interesse prioritário regional. De outro lado, é fundamental o direcionamento de esforços para a concepção e execução de uma política setorial específica que contemple a temática de integração mais relevante para os países, para que, assim, essa possa servir enquanto eixo ou norte de todo o processo.

\section{A política agrícola COMUM COMO EIXo Da INTEGRaÇão EUROPEIA: UMA QUESTÃo POLÍTICA IMPORTANTE}

A Política Agrícola Comum (PAC) é uma das políticas públicas comunitárias idealizadas pelo Tratado da Comunidade Europeia. De acordo com Lessa (2003, p.171), essa é a mais complexa das políticas comunitárias, na qual se observa a maior transferência de competências nacionais para instâncias supranacionais. Isso porque a política agrícola é aquela que mais absorve recursos do orçamento comunitário, que tem quase a metade dos seus recursos comprometidos com a política de subsídios agrícolas.

Considerada de forma objetiva, a relevância conferida à PAC no âmbito da União Europeia parece excessiva, sobretudo porque a agricultura apenas corresponde a $2,5 \%$ do seu PIB e a 5,2\% dos empregos (PORTO, FLÔRES JR., 2006, p. 136-140).

A despeito dessa aparente contradição, há muitos fundamentos que justificam a manutenção da PAC no lugar de destaque em que se encontra dentre as políticas públicas comunitárias. A questão da segurança alimentar no pós-Segunda Guerra foi um dos fatores que mais impulsionou a idealização de uma política agrícola comum. De outro lado, as necessidades de proteger as tradições de produção e controlar as pressões sociais decorrentes do êxodo rural também contribuíram para isso.

O enfrentamento dessas questões de forma conjunta tem permitido aos países europeus a elaboração de mecanismos mais eficientes do que aqueles que poderiam ser elaborados no âmbito de cada Estado isoladamente. Isso porque com a atuação conjunta ganha-se um peso e uma projeção imponentes que tornam a PAC não propriamente inatacável frente a terceiros países, mas certamente uma realidade difícil de ser relativizada (LESSA, 2003, p. 172). 
Nesse esteio, pode-se perceber dois importantes efeitos que decorrem da criação e do fortalecimento de blocos de países por intermédio de um eixo temático. De um lado, a adoção comunitária de uma política, enquanto resultado da aproximação política entre Estados, confere maior articulação e eficiência à implementação de um objetivo setorial. De outro lado, a própria política comunitária retroalimenta o processo de integração política, uma vez que cria e aprofunda vínculos entre os Estados que a adotam.

A PAC, assim, se tornou um dos mais significativos eixos da integração política e econômica europeia. Dessa forma, a instituição de uma política altamente protecionista e intervencionista, no seio de um processo de integração regional calcado em paradigmas liberais, revela o fundamental papel que o Estado desempenha, mesmo quando o objetivo é fortalecer instituições e mecanismos supranacionais que se adequam à livre circulação de mercadorias, bens e serviços. Dessa maneira, a experiência de integração europeia em boa medida se enquadra na perspectiva regional-desenvolvimentista, analisada no capítulo anterior.

No que concerne à América Latina, todavia, é fundamental que a região avance na concepção e execução de políticas comunitárias setoriais com o objetivo de construir bases sólidas para o desenvolvimento sustentado da integração latino-americana, no bojo dos esquemas de integração já existentes ou, ainda, por intermédio da criação de um novo processo de integração que tenha uma política setorial como norte das ações políticas.

\section{Da INTEgRaÇão ENERGÉTICA À INTEGRAÇão POLÍtiCa: A ADOÇão DE UMA POLÍTICA ENERGÉTICA COMUM COMO EIXO DA INTEGRAÇÃO REGIONAL SUL-AMERICANA}

Conforme mencionado anteriormente, as experiências de integração regional latino-americanas, por diversos fatores já analisados, têm, em geral, confluído para uma situação de apatia ou debilidade que caracteriza a insustentabilidade dos modelos de integração geralmente adotados. De outro lado, a experiência de integração europeia, sobretudo o processo que originou a atual União Europeia (UE) pode contribuir, em boa medida, para a superação de alguns obstáculos postos a uma maior convergência política na América do Sul.

Nesse sentido, pode-se mencionar o papel que teve a PAC para a consolidação política da UE, servindo como importante eixo de sustentação do processo de integração como um todo, conforme analisado no capítulo anterior. Além da PAC, como exemplo exitoso de integração regional setorial pode-se ainda remeter à Comunidade Europeia do Carvão e do Aço (CECA), esquema de integração voltado ao setor energético que teve significativa influência nos rumos da integração política da Europa.

Com relação à América do Sul, comparativamente à experiência europeia, percebe-se que a região tem um expressivo potencial de avanço na sua integração, desde que o processo seja conduzido com base num modelo regional-desenvolvimentista. Além disso, é fundamental que os países sul-americanos perfilhem conjuntamente a ideia de criação de uma vigorosa política setorial que guie e sustente o processo de aproximação regional, uma vez que esse naturalmente encontrará muitos óbices ao seu desenvolvimento. 
Assim, o setor energético desponta como sendo de grande oportunidade para que os países sul-americanos possam convergir ações e esforços com o objetivo de instituírem uma Política Energética Comum (PEC), que se torne o principal eixo da integração regional. Esse setor é altamente relevante para a América do Sul por duas razões principais. Por um lado, os países da região têm um importante potencial energético, assentado numa grande diversidade de fontes energéticas, bem como um expressivo volume de recursos existentes para cada fonte.

De outro lado, os recursos energéticos, contemporaneamente, são imprescindíveis ao desenvolvimento econômico de qualquer país, sobretudo à manutenção da posição galgada pelos países desenvolvidos. Assim, parece inconveniente que os países sul-americanos continuem exportando seus recursos energéticos de forma absolutamente aleatória e descoordenada, quando poderiam utilizar seu potencial na área de energia para impulsionar o desenvolvimento regional.

Deve-se mencionar, ainda, que uma PEC mostra-se viável no atual contexto sul-americano, além de ter potencial de ser extremamente salutar para a região. De acordo com Schaposnik:

O setor público, em muitos países, já tem uma posição dominante em muitos subsetores estratégicos que podem ser ampliados à ordem regional, aumentando, dessa forma, sua eficiência. Não há dúvida de que isso já é possível no setor de serviços de transporte, de energia, de produção de petróleo (...). (1997. p.143).

A ação conjunta dos Estados sul-americanos no estratégico setor de energia, dessa forma, elevaria a eficiência das políticas nacionais já existentes, além de ter a possibilidade de criar mecanismos regionais de articulação setorial, fortalecendo ainda mais a posição sul-americana nos mercados de energéticos.

São essas perspectivas que devem estimular a América do Sul a cerrar fileiras em torno de uma Política Energética Comum que, além de servir ao desenvolvimento regional por intermédio de uma atuação internacionalmente coordenada, poderá tornar-se o eixo principal de condução da aproximação política sul-americana. Desse modo, uma eventual implementação exitosa da PEC na América do Sul poderia conferir intenso e renovado ânimo à integração política regional, pelo que o sucesso da integração energética setorial "transbordaria" para o processo político, tal como ocorreu com a PAC na Europa.

\section{Breve anÁlise do POTENCIAL ENERgético dos PAíses SUl-AMERICANOS}

De acordo com dados de 2006, a América Latina como um todo foi responsável por $9,0 \%$ da produção mundial de óleo bruto, percentual quase duas vezes maior do que o da China $(4,7 \%)$ e duas vezes superior à produção da Ásia (excluindo-se a China, 4,5\%). No contexto sul-americano, destaca-se a Venezuela como oitavo produtor mundial de óleo bruto (3,8\%) e sétimo maior exportador desse importante recurso energético (IEA, 2007). Já no que concerne às reservas de petróleo, o conjunto da América Latina respondia, em 2006, por aproximadamente $10 \%$ das reservas mundiais, um número bastante expressivo no cenário internacional (OPEP, 2006). 
O conjunto da América Latina também possui reservas importantíssimas de gás natural, equivalente a $4,9 \%$ das reservas mundiais. Nesse caso, destaca-se a Venezuela, com mais da metade de todas as reservas da região, bem como a Bolívia e a Argentina, com menores, porém expressivos, estoques dessa fonte energética (OPEP, 2006). O setor de gás é muito relevante para a integração sul-americana, sobretudo porque tem capacidade para atender à demanda energética de uma série de indústrias, para abastecer frotas de veículos, para mover usinas termoelétricas destinadas à produção de eletricidade, suprir a demanda dos consumidores residenciais, entre outros.

Vale ainda salientar que a utilização de gás natural viabiliza a redução das emissões de gases causadores do efeito estufa e, consequentemente, contribui para a preservação do meio ambiente.

Por essas razões, a América do Sul deve caminhar de forma determinada para aumentar a integração física entre os centros produtores e consumidores de gás natural, superando, assim, os significativos entraves logísticos que atualmente restringem o comércio de energéticos na região.

A energia hidroelétrica, por sua vez, tem na América do Sul grandes oportunidades de expansão, inclusive por meio da celebração de parcerias entre os países sul-americanos, a exemplo do que ocorreu há cerca de 40 anos com a criação da Usina Hidroelétrica de Itaipu.

Com efeito, há ainda os combustíveis renováveis, que vêm sendo cada vez mais discutidos no mundo. Entre eles, destaca-se, na atualidade, o etanol, que poderá, em um futuro não muito distante, ter grande importância para o desenvolvimento socioeconômico da América do Sul. Em primeiro lugar, porque o Brasil é o maior produtor e detentor de tecnologia desse tipo de combustível. De acordo com a União da Indústria de Cana-de-Açúcar (UNICA), em 2006, o uso de etanol no Brasil atingiu 13,4 milhões de metros cúbicos, correspondendo a cerca de $40 \%$ do combustível utilizado em motores automotivos (UNICA, 2007). Os produtos energéticos oriundos da cana-de-açúcar também possuem expressiva representatividade na estrutura de toda a oferta brasileira de energia, da ordem de 14,5\% em 2006, percentual bastante superior ao ocupado pelo gás natural, de 9,6\% (MME, 2007).

Em suma, essa breve listagem das fontes energéticas predominantes na América do Sul já é suficiente para demonstrar que a região tem um efetivo potencial para beneficiar-se disso por meio de uma política setorial que contribuiria para o seu desenvolvimento socioeconômico e fortalecimento político internacional. Para que todo esse potencial seja adequadamente explorado, contribuindo para o desenvolvimento socioeconômico da América do Sul, a questão energética deverá ser prioridade de um esquema de integração regional abrangente tanto nos países que o compõe quanto na temática abordada. Sugere-se, portanto, que uma Política Energética Comum seja gestada no âmbito da recém-criada Comunidade Sul-Americana de Nações.

\section{A comunidade Sul-Americana de nações e a ampliação das perspectivas da INTEGRAÇÃO REGIONAL}

Em dezembro de 2004, durante a III Reunião da Cúpula da América do Sul, realizada no Peru, surgiu a Comunidade Sul-Americana de Nações (CASA). A Declaração de Cuzco, 
emitida após o evento, marcou a possibilidade de os 12 países sul-americanos se desenvolverem em um espaço integrado. A Declaração de Cuzco teve, ainda, o mérito de tentar superar a perspectiva de integração predominantemente comercial, conferindo nítida ênfase à integração física, energética e de comunicações na América do Sul.

No bojo da CASA, em setembro de 2005, reuniram-se em Caracas os ministros da Energia dos países envolvidos nessa iniciativa. A Declaração de Caracas, em seu preâmbulo, reconheceu que "apesar dos avanços que ocorreram em matéria de integração energética na América do Sul e do enorme potencial em recursos energéticos que possui a região, a América do Sul enfrenta ainda sérios desafios para assegurar o abastecimento energético" (MRE, 2007).

A mencionada Declaração enfatiza a proposta, feita pela Venezuela, de criação da Petroamérica, uma estratégia regional que seria voltada ao fortalecimento do setor energético como um todo (não apenas hidrocarbonetos). De acordo com a Declaração, "a estratégia Petroamérica busca ser um facilitador geopolítico fundamentado na identificação de mecanismos de cooperação e integração energética" (MRE, 2007), tendo por objetivo "ser um acordo multilateral para a coordenação de políticas energéticas com a finalidade de promover a integração regional e agilizar a tomada de decisões que conduzam à bemsucedida culminação dos processos de integração" (MRE, 2007).

Dessa maneira, esse documento manifesta um novo e importante direcionamento na condução do relacionamento entre os países sul-americanos, conferindo relevância ao setor energético enquanto tema que, por haverem interesses convergentes, aproxima os países da região, tendo, assim, potencial para constituir um eixo fundamental da integração da América do Sul. Posteriormente, em abril de 2007, foi realizada a Cúpula Energética da CASA, que reuniu, na Ilha de Margarita, Venezuela, os chefes de Estado e de governo dos 12 Estados soberanos da América do Sul para discutir a integração energética regional.

A integração energética sul-americana, assim, é entendida como importante para o desenvolvimento regional de um setor específico (energético), mas também como instrumento de convergência de interesses e ações concretas que culminem com a consolidação da CASA para que se alcance a unidade sul-americana.

Assim, negociações preliminares que envolvem principalmente o Brasil, a Argentina e a Venezuela para a implementação do Gasoduto do Sul, uma obra que consumiria aproximadamente 20 bilhões de dólares e que teria uma extensão entre 7 a 9 mil quilômetros, passando por boa parte dos países sul-americanos (GAWORA, 2006).

A realização do Gasoduto do Sul, por ora, ainda depende da aprovação dos países interessados nessa iniciativa. No particular, ingresso da Venezuela no Mercosul e a aproximação desse bloco com a Comunidade Andina poderá contribuir para o avanço das negociações. De antemão, pode-se afirmar que o projeto tem expressivo potencial de aprofundar sobremaneira a integração regional sul-americana a partir da integração energética, o que fortaleceria a União de Nações Latino-Americanas (UNASUL), rumo a sua institucionalização.

Dessa forma, a integração energética sul-americana tem caminhado de forma relativamente satisfatória, a partir, inclusive, da percepção de que esse pode ser um setor 
que venha a constituir um eixo da integração sul-americana. A despeito disso, carece a integração energética sul-americana de uma política supranacional consistente e com objetivos bem definidos que balize a ação conjunta dos Estados. A ausência de planejamento compartilhado para o setor, por sua vez, tem levado a uma falta de coordenação e coesão que tem dificultado o desenvolvimento de ações concretas nessa área, a exemplo da integração física das matrizes energéticas sul-americanas.

As recentes movimentações, sobretudo do Brasil e da Venezuela, no sentido de intensificar a integração energética regional, contudo, apontam para uma perspectiva auspiciosa para a América do Sul. Desde que essas iniciativas com o tempo mostrem não atenderem apenas ao exercício de retórica dos líderes políticos sul-americanos, a região terá na integração energética um instrumento de grande utilidade para a consolidação da sua união política e econômica.

\section{Linhas gerais Para A AÇão CONJUNTA dOS PAíses SUl-AMERICANOS NO SETOR ENERGÉTICO}

Para que os países sul-americanos avancem na construção de uma efetiva Política Energética Comum, as iniciativas tomadas nessa área devem ser coordenadas e sistêmicas, tendo em conta a complementaridade existente entre as matrizes energéticas dos países sul-americanos.

Além disso, a integração energética sul-americana é premente para atender à crescente demanda de energia originada pelo crescimento econômico da própria região. No particular, o Brasil e a Argentina, as duas economias mais pujantes da região, investiram aquém do necessário em infraestrutura energética nas últimas décadas, o que tornou seu desenvolvimento dependente da importação de energéticos dos países vizinhos, como Bolívia, Venezuela e Peru. Dessa forma, a convergência da América do Sul nesse tema é também fundamental sob o ponto de vista do suprimento do mercado regional de energéticos, especialmente em relação ao abastecimento de gás natural.

A integração energética sul-americana, portanto, deve partir da formulação de uma Política Energética Comum (PEC) que estabeleça as diretrizes de atuação conjunta dos países, com ações, objetivos e metas bem definidos. No que concerne às ações nesse sentido, propõe-se: 1) a constituição de um fundo regional de fomento à integração da infraestrutura energética sul-americana; 2) o aprofundamento da cooperação entre os países da região em matéria energética, envolvendo, inclusive, transferência de tecnologias; 3 ) o estabelecimento de vínculos entre as empresas estatais de energia que possibilitem a permanente articulação nos mercados internacionais e o desenvolvimento de parcerias; 4) implementação, no bojo da PEC, de uma bolsa de valores voltada ao mercado regional de commodities energéticas; 5) a articulação de posicionamentos concertados no plano internacional no que se refere à dinâmica dos mercados energéticos; 6) a criação de um fórum permanente para conduzir e avaliar a PEC, composto pelos chefes de Estado da região, bem como pelos ministros de Energia dos Estados e pelos presidentes das companhias estatais do setor energético. 


\section{Da integração energética À integração política na América do Sul}

A adoção de uma política energética comum, além de importante para o desenvolvimento dos países, pode, ainda, ser muito útil como eixo setorial da integração sul-americana. Esse aspecto remete à experiência da Comunidade Europeia do Carvão e do Aço (CECA), criada em 1951, que veio a ser o embrião da atual integração europeia. De acordo com Porto e Flôres Jr. (2006. p. 15), a CECA, a partir de uma perspectiva setorial, viabilizou um espaço de negociação entre seus países-membros, abrindo caminho ao movimento maior de integração iniciado com a Comunidade Econômica Europeia (CEE).

Ainda de acordo com aqueles autores, na formação da CECA foi determinante o reconhecimento da importância estratégica dos dois setores (carvão e aço) dos pontos de vista econômico e militar, devendo por isso ser colocados sob responsabilidade comunitária (PORTO, FLÔRES JR., 2006. p. 165). Desse modo, atendendo aos seus interesses estratégicos de então, os países fundadores da CECA entre si estabeleceram uma política comum que, além do aço, cuidava da fonte energética então dominante, o carvão, cujas reservas suscitavam conflitos entre os países. Os países precursores da CECA, portanto, utilizaram, com êxito, a integração regional num setor específico como instrumento de superação dos conflitos regionais e de convergência de interesses e esforços políticos.

Conforme já referido, a Política Agrícola Comum no âmbito da CEE também contribuiu de forma bastante expressiva como eixo para a consolidação política da integração daquele processo, que culminou com a atual União Europeia.

Essas experiências europeias partiram de uma percepção ampla da integração regional, não se restringindo à aplicação de mecanismos de liberalização do comércio e da economia regional. De forma contrária, a integração europeia prezou por uma cautelosa seleção de setores ou esferas a serem integradas (BIEBER, 1993, p. 8), seleção essa que foi funcional à continuidade e ao aprofundamento da integração. Nesse aspecto, a América do Sul não teve uma experiência semelhante à europeia:

(...) a prática integracionista ficou reduzida a exercícios técnico-burocráticos sobre reduções alfandegárias e sobre projetos conjuntos de cooperação na área industrial, como aconteceu no caso do Pacto Andino e, mais recentemente, no contexto do Mercosul, sem que essas ações chegassem a atingir uma projeção verdadeiramente político-histórica (BIEBER, 1993, p. 9).

Assim, a proposta ora apresentada de adoção da PEC na América do Sul pode ser justificada essencialmente pela necessidade de utilização mais adequada do elevado potencial energético detido pelos países sul-americanos. Dessa forma, para dentro da região, é salutar que os países sul-americanos intensifiquem a integração das suas matrizes energéticas visando a aumentar o intercâmbio de recursos. Para fora, é premente a articulação sistêmica do posicionamento sul-americano nos mercados energéticos internacionais. Os resultados dessas medidas poderiam ser, respectivamente, 1) a estabilização do mercado regional de energia (oferta e demanda), criando condições para a sustentabilidade do crescimento econômico nos países; e 2) o fortalecimento da América do Sul no cenário internacional enquanto global player coeso e integrado ao setor energético. 
Além desses resultados, relacionados ao setor energético propriamente dito, o sucesso da PEC poderia "transbordar" para a integração política sul-americana, uma vez que criaria um novo patamar de negociações entre os países da região, consubstanciado pelo êxito da integração num setor extremamente estratégico para o desenvolvimento socioeconômico nacional (vide as experiências da PAC e da CECA, anteriormente analisadas).

Vale mencionar que a proposta de implementação de uma política setorial, a exemplo da PEC, obviamente, não solucionará os crônicos problemas de desenvolvimento e inserção internacional existentes na América do Sul. Uma política energética consistente no âmbito regional, contudo, contribuiria para a retomada, nos países sul-americanos, do poder decisório do Estado sobre seus próprios rumos, tendo em conta um modelo de integração regional-desenvolvimentista.

\section{ConsideraÇões Finais}

A realidade socioeconômica atualmente posta na América do Sul é desafiadora e demanda uma atuação ativa, articulada e compartilhada dos Estados nacionais. Com isso, a região poderá usufruir melhor dos seus significativos recursos naturais, entre os quais têm grande relevância os recursos energéticos. Essa afirmação parte da constatação de que à América do Sul não cabe mais o papel de periferia do sistema internacional, mas de protagonista, pari passu com as grandes potências mundiais.

Isolados, contudo, os Estados sul-americanos permanecerão subordinados a políticas e diretrizes originárias do exterior e que, sem adequar-se à realidade regional, historicamente têm sobrestado o desenvolvimento socioeconômico desses países.

A integração regional, pois, pode desempenhar um importante papel no contexto da América do Sul, sobretudo se for superada a noção de que o paradigma liberal é o único norte da integração, percebendo-se que com base nesse a integração fica subordinada à evolução das trocas comerciais entre os países. Ao contrário das experiências vividas no passado recente da integração sul-americana, a PEC pressupõe a atuação dos Estados como atores centrais da integração regional.

Partindo desses pressupostos, a Política Energética Comum proposta neste trabalho pode contribuir em boa medida como instrumento de superação de dois permanentes entraves ao desenvolvimento sul-americano: a dependência externa e o isolacionismo. Conforme mencionado, a PEC poderá alçar a América do Sul a uma nova condição no sistema internacional, mais soberana, autônoma e altiva. De outro lado, essa política setorial criaria mecanismos de aproximação entre os países da região que, com o tempo, poderiam cooperar com o processo político sul-americano, fomentando-o.

A PEC, nesse sentido, é proposta enquanto política-eixo da integração sul-americana, criando externalidades positivas para o conjunto das relações políticas estabelecidas entre os países que vierem a adotá-la.

No que concerne às linhas gerais propostas neste trabalho para a ação dos Estados sul-americanos no setor energético, essas constituem apenas sugestões e provocações, uma 
vez que, tratando-se de um setor técnico de extrema complexidade, apenas análises mais apuradas poderiam encaminhar propostas efetivamente factíveis.

Os pontos levantados, todavia, servem à reflexão da gama de possibilidades e estratégias, ainda inexploradas, que estão à disposição dos países sul-americanos no setor energético. Além disso, ainda que estudos técnicos de qualidade venham a ser elaborados, a concretude de tudo que for proposto dependerá da ação efetiva dos líderes políticos, que se manifestam por meio de seus Estados, e atendendo às diretrizes almejadas pelo povo sul-americano.

Por fim, as questões aqui tratadas servem, ainda, como provocação diante da grande contradição sul-americana, região que possui significativos recursos naturais, uma expressiva população, um território vasto, etc., e, a despeito disso, não tem conseguido superar históricas desigualdades sociais que a impedem de se tornar uma região desenvolvida.

\section{REFERÊNCIAS BIBLIOGRÁFICAS}

BANCO INTERAMERICANO DE DESENVOLVIMENTO. Uma perspectiva otimista para a energia. Disponível em: <http://www.iadb.org/idbamerica/index.cfm?thisid=4247> Acesso em: 20.10.2007.

BATISTA JR., Paulo Nogueira. A América do Sul em movimento. Rio de Janeiro: FUNAG, IPRI, 2006. BIEBER, León E. Europa e América Latina: análise comparativa dos processos históricos de integração. RBPI, n. 1, 1993.

BRAGA, Márcio Bobik. Integração econômica regional na América Latina: uma interpretação das contribuições da CEPAL. Cadernos PROLAM/USP, n. 1, 2002.

CARÍSIO, Maria Clara Duclos. A evolução da política agrícola comum da UE e os interesses brasileiros. Brasília: IRBr, Funag, 2006.

GAWORA, Dieter. O gasoduto Venezuela - Brasil — Argentina. Revista Espaço Acadêmico, n. 60, maio 2006.

HOLLANDA FILHO, S. B. Livre comércio versus protecionismo: uma antiga controvérsia e suas novas feições. Estudos Econômicos, São Paulo, v. 28, n. 1, p. 33-75, 1998.

IEA. Key world energy statistics 2007. Paris: OECD, 2007.

LESSA, Antônio Carlos. A construção da Europa: a última utopia das relações internacionais. Brasília: IBRI, 2003

MENEZES, Alfredo da Mota; PENNA FILHO, Pio. Integração regional: os blocos econômicos nas relações internacionais. Rio de Janeiro: Elsevier, 2006.

MERCOSUL. Tratado de Assunção. Promulgado no Brasil pelo Decreto n. 350, de 21 de novembro de 1991. Disponível em: <http://www2.mre.gov.br/dai/trassuncao.htm>. Acesso em: 19.11.2007.

MINISTÉRIO DE MINAS E ENERGIA. MME. Balanço Energético Nacional 2007. Resultados Preliminares. Disponível em: <http://www.mme.gov.br/frontSide/site/view.do?viewPublicationId $=14131$ \&viewPublication TypeId=9\&queryUrl $=\mathrm{http} \% 3 \mathrm{~A} \% 2 \mathrm{~F} \% 2 \mathrm{Fwww}$.mme.gov.br\%2F site\%2 Fsearch.do\%3 Fquery\%3Dben> Acesso em: 22.11.2007.

MRE. Declaração de Caracas. Disponível em: <http://casa.mre.gov.br/documentos/i-reuniao-dechefes-de-estado/declaracao-de-caracas-no-ambito-da-i-reuniao-de-ministros-de-energia-dacomunidade-sul-americana-de-nacoes> Acesso em: 22.10.2007. 
. Declaração de Margarita. Disponível em: < http://www.flacso.org.br/index.php?id=1611> Acesso em: 22.10.2007.

MUÑOZ, Guillermo Maya. Proteccionismo agrícola y dumping social. Investigación Económica, v. LVII, n. 219, p. 85-13, ene./mar. 1997.

OCDE. Agricultural policies in OECD countries - at a glance 2006. Paris: OCDE, 2006.

OPEP. Organização dos Países Exportadores de Petróleo. Annual Statistical Bulletin 2006. Viena: OPEC, 2006.

PEÑA, Félix. Los grandes objetivos del Mercosur: zona de livre comercio, unión aduaneira y mercado común. In: BARBOSA, Rubens A. (org.). Mercosul: quinze anos. São Paulo: Fundação Memorial da América Latina, Imprensa Oficial do Estado de São Paulo, 2007.

PETROBRÁs. Petróleo Brasileiro S/A. Área de Negócios de Exploração E̊ Produção - E छ̉P. Disponível em: <http://www2.petrobras.com.br/portal/frame.asp?pagina=/Petrobras/portugues/ perfil/per_atuacao.htm\&lang=pt\&area=petrobras $>$ Acesso em: 22.10.2007.

PORTO, Manoel Carlos Lopes; FLÔRES JR., Renato Galvão. Teoria e políticas de integração na União Europeia e no Mercosul. Rio de Janeiro: FGV, 2006.

ROSENTHAL, Gert. Un informe crítico a 30 años de integración en América Latina. Nueva Sociedad, n. 113, p. 60-66, may./jun. 1991.

RUAS, José Augusto Gaspar. Elementos para uma nova agenda de pesquisas de integração energética no Mercosul: o caso da indústria de gás natural. In: Energia para o Mercosul: edição 2004 do Prêmio Mercosul de Ciência e Tecnologia. Brasília: UNESCO, 2005.

SCHAPOSNIK, Eduardo C. As teorias da integração e o Mercosul: estratégias. Florianópolis: UFSC, 1997.

SICA, Dante. Mercosur evolución y perspectivas. In: BARBOSA, Rubens A. (org.). Mercosul: quinze anos. São Paulo: Fundação Memorial da América Latina, Imprensa Oficial do Estado de São Paulo, 2007. p.45-99.

STANGANELLI, Isabel; REYES, M. Integración de las redes de gás natural en el Cono Sur. In: LIMA, M. C.; MEDEIROS, M. A. (orgs.). O Mercosul no limiar do século XXI. São Paulo: Cortez, 2000.

ÚNICA. Produção e uso do etanol combustivel no Brasil. São Paulo: Unica, 2007. 
